\title{
Validity of injury data collected by interview: a study of men born in 1913 and 1923
}

\author{
GUDRUN SILVERBÅGE CARLSSON \\ From the Department of Neurosurgery, University of Göteborg, Sahlgren's Hospital, Göteborg, Sweden
}

SUMMARY An investigation of the validity of anamnestic injury data with special reference to head injuries, was performed, as part of an epidemiological population study of middle aged men. Injury data collected by interview were checked against control data from an emergency department, covering a 7-year period. About $65 \%$ of head injuries in the control data set, and $60 \%$ of all types of injuries were reported. Injury severity, alcohol intoxication, ambulance transportation and recall period were factors which tended to influence the reporting frequency.

Questions concerning possible previous head injuries, are part of the examination of most neurosurgical, neurological and psychiatric patients. However, the validity of such information is insufficiently known. One of the more important aspects is to what extent interview data measure injuries which have actually occurred.

Within the framework of the Study of Men Born in 1913 and $1923^{1}$, which is a prospective study on more than one thousand men born in 1913 and 1923, sampled from the general population of Göteborg, Sweden, an epidemiological investigation of head injuries has been performed. One of the aims of the investigation was to arrive at descriptive statistics of head injuries during the life time of the men in the two samples. To estimate the frequency and significance of head injuries in relation to other injuries, all types of injuries were included in the investigation. A life history of injuries was obtained from the subjects by means of a structured interview.

This study offered an opportunity to perform a validation $^{2}$ of anamnestic head injury data, that is the extent to which the interview data measured the actual occurrence of injuries.

\section{AIMS OF THE STUDY}

The purposes of the validation study were: (1) to study the extent to which injuries resulting in medical attendance were reported at the interview. (2) to

Address for reprint requests: Gudrun Silverbåge Carlsson, MD Department of Neurosurgery, Sahlgren's Hospital, S-413 45 Göteborg, Sweden

Received 18 November 1983 and in revised form 7 April 1983. Accepted 14 April 1983. study factors possibly affecting the recall frequency of injuries.

\section{STUDY POPULATIONS}

All residents in Sweden have a national registration number. Names, addresses and registration numbers are registered by the County Census Bureau in a population register. From this population register two samples were drawn in 1973. The first sample consisted of males, living in Göteborg, Sweden, who were born in 1913 on a date divisible by three; the third, sixth, ninth day and so on, in each month. 945 men met these criteria. Of these, $765(81 \%)$ participated in this part of the study and were examined at the Sahlgren's Hospital in Göteborg. The second sample comprised men born in 1923 on the third, the fifteenth or the twenty-seventh day of each month and who were living in the city of Göteborg. Of 292 men meeting these criteria $219(75 \%)$ men agreed to be examined. These two population groups have been described in detail elsewhere. ${ }^{34}$

\section{Methods}

For the validation process two sets of data were used: accident data from the register and from the records of an emergency department and the corresponding data obtained by interviews of the men in the two samples.

Interview data Collection. The interview data were collected from February, 1973 to April, 1974. Enclosed with the invitation letter was a form in which the participants were asked to list, at home, all the injuries (fulfilling the criteria mentioned below) that they had sustained during their lifes. This form was then used as a memory support at a structured interview, which was performed at the Sahl- 
gren's Hospital in the early afternoon by one of five doctors. All injuries fulfilling the criteria were recorded during the interview on a special injury form.

Interview variables. The following variables were used in the interview: age at the time of the accident, body region injured, type of medical attendance, civil status, income, occupation, education.

Injury concepts. Injuries to be recorded were: (1) all head injuries resulting in unconsciousness. (2) all injuries which had caused restricted activity for one day or more. (3) all injuries for which the proband had sought medical attendance. A maximum number of ten accidents were fully recorded per participant and for each accident a maximum of five injuries. None of the participants in the validity study reported more than ten accidents or more than five injuries per accident.

\section{Register data}

Data source. During the time period covered by this study Sahlgren's Hospital was the only hospital in the city with a surgical emergency department for adults open for twenty-four hours through the week. A number of small outpatient clinics and one small hospital also provided attendance during day-time for patients with chiefly minor injuries.

For this study the patient register of the emergency department of the Sahlgren's Hospital was chosen as the data source. Ideally, register data from all units should have been used. However, the retrieval systems of the clinics outside the Sahlgren's Hospital were unsuitable for finding medical records for a specified disease entity in a defined population during a defined period of time. Therefore only data from the Sahlgren's Hospital were used.

All visits to the emergency department of Sahlgren's Hospital are noted in a register book. Register data were available from 1966 and were used for the purpose of this study until 1972. In this presentation "register injuries" denote injury data derived from the register books.

Register variables. From the register all events involving men of the two samples were extracted. The following variables were used: age at the time of attendance, means of transportation to the hospital, notes on alcohol intoxication, diagnosis, type of treatment (orthopaedic, plastic or ENT), type of care (outpatient care or hospitalisation).

The register diagnosis was either transferred from the medical record or made by a nurse after information from the patient. The note on alcohol intoxication was based on judgement by the nurses in the emergency department which implied evidently drunken patients.

Definition of injury severity. Based on the register diagnoses the injuries were classified as major, minor or moderate and the following criteria were used: major: injuries involving fractures (except rib fractures), burns, skull injuries with loss of consciousness and all types of injuries when ambulance transportation was used or when the patient was admitted to hospital care, minor: superficial skin wounds, foot and hand distorsions, insect or other minor animal bites, moderate: all injuries not "major" or “minor", and minor ones if orthopedic, plastic or ENT surgical care was necessary.

In multiple injuries the most serious injury was used for this study. When equally serious the first one noted in the register book was used.

Matching. The events in the register data set were matched with those in the interview data set. The following prespecified criteria for matching were set up: (1) agreement about injury location (2) agreement about age at the time of the accident \pm 5 years. For incomplete matches further information about the type of injury and accident was collected from the medical records and the interview data. The number of patients included after check-up and the reason for the initial non-match are listed in table 1.

Statistical methods. Differences between means were tested by Student's $t$ test and differences in proportions by the Chi-square test. For the analysis of trends Fischer's trend test was used. p values of 0.05 or less were regarded as denoting statistical significance. Differences mentioned in the text are significant only if so noted or if a $p$ value is given.

\section{Results}

\section{Distribution of register data}

The register data set contained 65 injuries registered for 53 of the fifty-year-old men and 206 injuries for 165 of the sixty-year-old men. As only the most serious injury was registered in accidents with multiple injuries the number of injuries is equal to the number of accidents in this presentation. Accidents with multiple injuries were found in $4 \%$ of the reported accidents and in $2 \%$ of the non-reported accidents among sixty-year-old men. The corresponding numbers for the fifty-year-old men were 5 and $4 \%$ respectively.

Table 1 Reasons for initial non-match and number of patients included as matches after check up.

\begin{tabular}{lll}
\hline Reasons for a non-match & \multicolumn{1}{c}{ Number of patients } \\
\cline { 2 - 3 } & $\begin{array}{l}50 \text {-year-old } \\
\text { men }\end{array}$ & $\begin{array}{l}60 \text {-year-old } \\
\text { men }\end{array}$ \\
\hline $\begin{array}{l}\text { Shortcomings in the register data } \\
\text { No diagnosis } \\
\text { Wrong diagnosis }\end{array}$ & 1 & 4 \\
$\begin{array}{l}\text { Incomplete diagnosis } \\
\text { a) single injury }\end{array}$ & 0 & 2 \\
$\quad \begin{array}{l}\text { b) one injury* in the register } \\
\text { matching one of two or more } \\
\text { in the interview }\end{array}$ & 9 & 5 \\
$\begin{array}{l}\text { Shortcomings in both register and } \\
\text { interview data } \\
\begin{array}{l}\text { One of two injuries* in the register } \\
\text { the other one in the interview }\end{array}\end{array}$ \\
$\begin{array}{l}\text { Shortcomings in the interview data } \\
\text { One injury* in the interview } \\
\text { matching one of two in the register }\end{array}$ & 9 \\
\hline
\end{tabular}

*in accidents with multiple injuries 
On account of small numbers, head injuries were analysed separately only when considered meaningful.

Table 2 shows the distribution of injury severity and location (head or other), the frequency of alcoholic intoxication and ambulance transport to the hospital.

Among the fifty-year-old men, $63 \%$ of the injuries found in the register data set were reported by the men. Among the sixty-year-old men the corresponding proportion was $60 \%$, table 3 .

\section{Register age and reported age}

The relation between the age at the time of the accident as indicated in the register and as reported by the men, is given in fig 1 . The agreement was fairly good with a correlation coefficient of $0.6(p<0.001)$ for the fifty-year-old men and $0.7(p<0.001)$ for the sixty-year-old men. There was a slight tendency for the men to overestimate the time lapse from injury to interview. $93 \%$ were reported within +-3 years.

\section{Recall period}

Injuries, occurring in the beginning of the period studied, tended to be reported to a somewhat lower extent than the more recent injuries, fig 2 . The trend was similar in both age groups, but it was weak and not statistically significant.

Injury severity, body location and multiple accidents. Figure 3 shows the frequency of reporting in relation

Table 2 Data from the register of the emergency department of Sahlgren's Hospital, 1966-1972.

\begin{tabular}{lrrrrr} 
& \multicolumn{2}{c}{50 -year-old men } & & \multicolumn{2}{c}{60 -year-old men } \\
\cline { 2 - 3 } \cline { 5 - 6 } & $n$ & $\%$ & & $n$ & $\%$ \\
\hline Injuries* & 65 & & & 206 & \\
Major & 22 & 33.8 & & 50 & 24.3 \\
Moderate & 9 & 13.8 & & 34 & 16.5 \\
Minor & 34 & 52.3 & & 122 & 59.2 \\
Head & 6 & 9.2 & & 51 & 24.8 \\
Other & 59 & 90.8 & & 155 & 75.2 \\
Ambulance & 5 & 7.7 & & 17 & 8.3 \\
Alcohol & 3 & 4.6 & & 13 & 6.3 \\
\hline
\end{tabular}

*Number of injuries=number of accidents as only the most severe injury was used in accidents with multiple injuries.

Table 3 Number of injuries in the index data reported and not reported at interview

\begin{tabular}{|c|c|c|c|c|c|c|}
\hline \multicolumn{4}{|c|}{$\begin{array}{l}\text { Interview data } \\
\quad 50 \text {-year-old men }\end{array}$} & \multicolumn{3}{|c|}{ 60-year-old men } \\
\hline & reported & $\begin{array}{l}\text { not } \\
\text { reported }\end{array}$ & total & reported & $\begin{array}{l}\text { not } \\
\text { reported }\end{array}$ & total \\
\hline \multicolumn{7}{|c|}{$\begin{array}{l}\text { Register } \\
\text { data }\end{array}$} \\
\hline $\begin{array}{l}\mathrm{n} \\
\%\end{array}$ & $\begin{array}{l}41 \\
63\end{array}$ & $\begin{array}{l}24 \\
37\end{array}$ & $\begin{array}{r}65 \\
100\end{array}$ & $\begin{array}{r}123 \\
60\end{array}$ & $\begin{array}{l}83 \\
40\end{array}$ & $\begin{array}{l}206 \\
100\end{array}$ \\
\hline
\end{tabular}

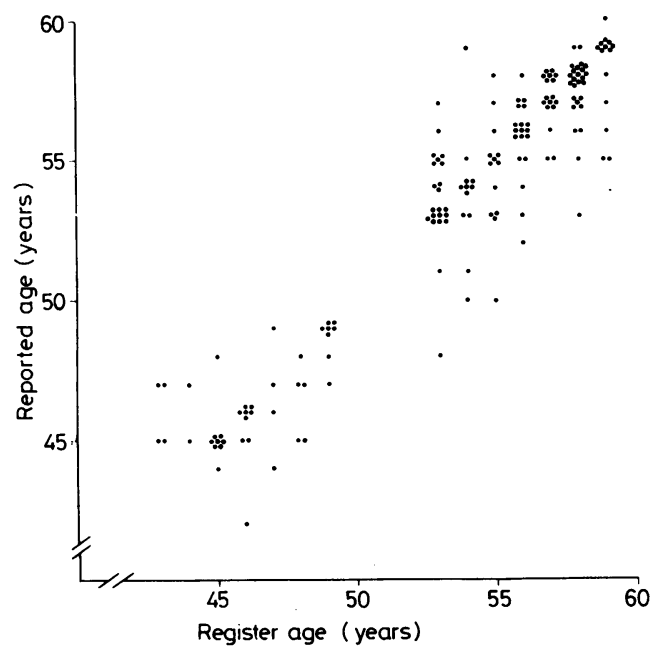

Fig 1 Age registered in the index data and age reported at interview.

to the severity of the injury. Both age groups reported a little less than half of the minor injuries whereas the major injuries were reported in $85 \%$. Moderate injuries were reported in $89 \%$ by the fifty-year-old men, $58 \%$ by the sixty-year-old men and in $72 \%$ in the combined group. The difference in reporting frequency between the severity groups was significant $(\mathrm{p}<0.001)$.

Head injuries tended in both samples to be more frequently reported than injuries to other parts of the body, in $65 \%$ versus $59 \%$ for the samples together. The difference was not significant. However, when account was taken of the severity of the injury, head injuries were somewhat more frequently reported in the minor lesion group and somewhat less frequently regarding the more severe lesions, fig 4.

There was no relationship between frequency of reporting and number of accidents per proband. However, very few men (two in each population) had more than two accidents in the register data set.

Alcohol intoxication and ambulance transportation. Register injuries with a note on alcohol intoxication were reported to a lower extent than other injuries, $44 \%$ versus $62 \%$, fig 5 . Transport by ambulance to the emergency ward was associated with a higher frequency of reporting than other means of transportation, $73 \%$ versus $59 \%$. The influence of ambulance transportation on the reporting was also analysed separately among the intoxicated and the non-intoxicated men. As shown in fig 6 this influence was different in the two groups. Among 


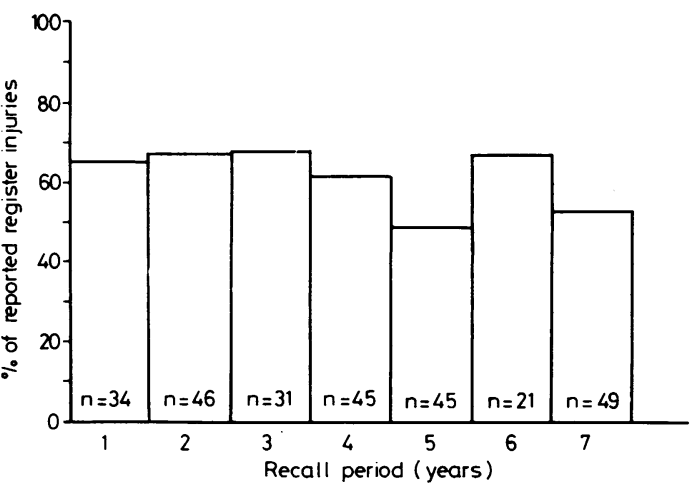

Fig 2 Proportion of register injuries reported at interview in relation to the time interval between accident and interview. $n$ indicates the number of register injuries for each year.

the non-intoxicated men transport by ambulance was associated with a high degree of reporting, while in the intoxicated group the difference between those transported by ambulance and other men were small.

\section{Social variables}

There was no significant difference regarding reporting frequency with reference to civil status, income or social class, based on education and occupation.

\section{Discussion}

Thus, about $60 \%$ of all injuries found in the register

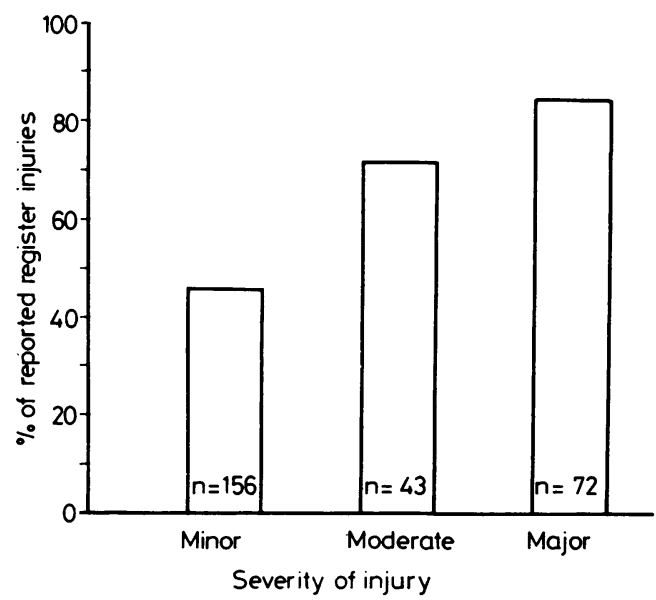

Fig 3 Proportion of register injuries reported by the participants in relation to severity of injury. $n$ indicates the number of register injuries in each group.

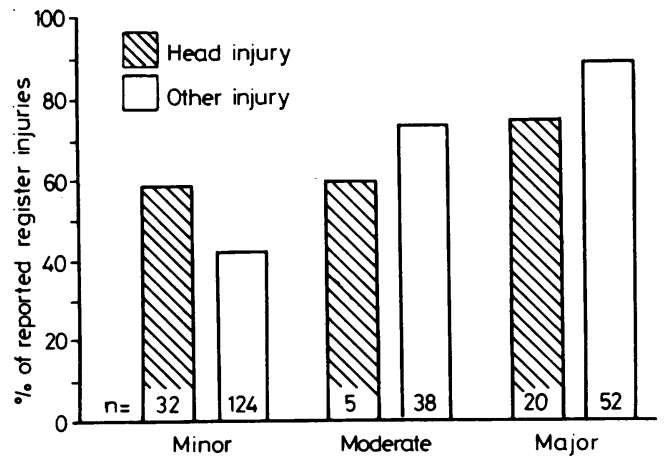

Fig 4 Proportion of register injuries reported in relation to severity of injury and location.

data set were reported by the probands. Factors which tended to be associated with a higher reporting frequency were severe injuries, head injuries compared to other injuries, short time interval between accident and interview, ambulance transportation to the hospital and no signs of alcohol intoxication at the time of attendance. Civil status, income and social class did not seem to affect the reporting frequency.

\section{Possible bias}

Ideally medical record information should have been used as the index data. However, the retrieval system used at the hospital made it difficult to collect complete data for the time period and population

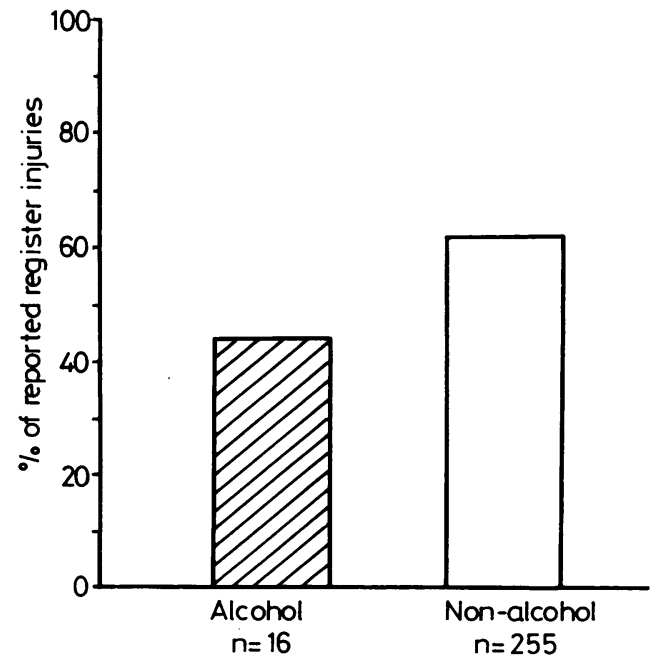

Fig 5 Proportion of register injuries reported in connection with severe alcohol intoxication at the time of attendance. 


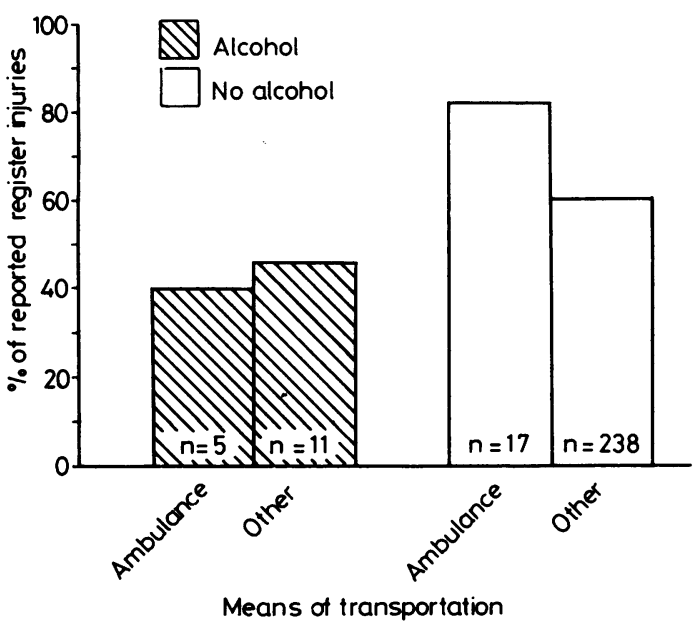

Fig 6 Proportion of register injuries reported in relation to means of transportation to hospital and register notes on severe alcohol intoxication at the time of arrival.

segment involved. Therefore, data from the register book were used. Since all patients attending the emergency department must be entered in the book, the coverage of the population and the time period was satisfactory. Since the diagnosis in the register book was not always transferred from the medical record, but sometimes made by the nurse after information from the patients, the diagnostic information in the register book was sometimes scanty. This may have caused an artificial non-match. Therefore, in all cases in this study, where the match was not perfect, the diagnosis was checked in the medical record as described in the method section. The bias due to diagnostic inaccuracy in the index data is therefore probably small.

Many factors associated with the proband, the interviewer and with conditions related to the design of the study may affect the validity of the interview data. $^{56}$ The most obvious possible bias is memory failure. To minimise this bias a memory form was mailed in advance to the participants, giving them more time to remember and the possibility to confer with relatives.

Withholding of information is another possible source of bias, but generally injuries have little or nothing of taboo concepts and therefore this source of bias is probably of little importance.

A third possible bias is observer variation. The structured interview performed at the same time of the day, equally distributed over the seasons, and regular contacts among the five interviewers aimed at getting uniformly collected data. There were small differences in mean number of registered acci- dents between interviewers. Thus, no obvious bias appears to have influenced the data collection process.

Study design and representativity of results.

Interview data on injuries not resulting in medical attendance could not be verified against index data and could thus not be validated. An ideal validation would have included a two-way cross tabulation of interview positives and negatives against index positives and negatives. However, as index data were fully available only from the Sahlgren's Hospital and not from the other clinics, the validation was restricted to a one-way analysis of register data from a section of the medical care system versus interview data.

Will then the presented reporting frequency of about $60 \%$ be representative also for injuries requiring attendance only in the out-patient clinics? 194 injuries of all types were reported by the participants to have caused medical attention during the 7year period, but could not be found in the index data. If, in the extreme case, all the 194 injuries all types were treated outside the Sahlgren's Hospital, consisted of minor injuries, and were reported to the same extent as minor ones in this study, then the overall reporting frequency in the population would be $53 \%$ instead of $60 \%$. As in reality also a certain proportion of moderate and major injuries (that is orthopoedic injuries and burns) were treated in the out-patient clinics the most realistic estimate would not be far from $60 \%$.

\section{Literature review}

The literature regarding the validity of injury data collected by interview is scarce. No study is quite comparable to this one and no one deals with head injuries separately. Most studies are household interview studies using laymen as interviewers and covering a broad spectrum of conditions. In household studies the data are not necessarily autoanamnestic.

Gordon et $\mathrm{al}^{7}$ in 1958/59 in India performed indirect measurements on reporting frequency of accidents in relation to recall period and injury severity. One population was interviewed every 2 weeks; the other one every 4 weeks. For injuries which caused permanent defect the reported incidences were almost identical between the populations, whereas for injuries which caused restricted activity for at least one day, but no permanent defect, a $38 \%$ lower incidence was obtained with the longer recall period compared to the shorter one.

A direct validation was made in the US Health Interview Survey performed in $1958 / 59 . .^{8}$ During a recall period of up to one year, hospitalisation for all 
sorts of diseases were asked for among persons known to have been in hospital during that period. The comparison to hospital records gave an underreporting of $17 \%$ regarding 50 hospital episodes for fractures and dislocations and $13 \%$ for 66 episodes for other current injuries. There was very good agreement regarding diagnoses. For all diseases together (injuries were not accounted for separately) there was a decrease of reporting with time during the year. Self respondents reported to a higher degree than proxy respondents.

In another study ${ }^{9}$ with chief interest in chronic conditions, performed in New York City households, by the Health Insurance Plan, interview data were compared to doctors reports. Of 33 injuries requiring medical attendance, (almost only office service), within 2 weeks prior to interview, $58 \%$ were reported.

As mentioned earlier none of the studies is directly comparable to the present one. The present study covers for instance a much longer time period but shows only a very weak decrease of recall frequency with time. On account of the design of this study the effects of short recall periods could not be studied. Thus a relatively fast decline in the reporting frequency may be possible with a shorter recall period and after that a "stabilisation" of the remembered events.

Injury severity as an important factor for reporting frequency finds support in the mentioned studies. The effect of alcohol intoxication or ambulance transport on the reporting frequency has not been studied in the literature referred to above. The lower reporting frequency with alcohol intoxication may be assumed to be due chiefly to amnesia due to the intoxication. The higher reporting frequency for ambulance transport to the department probably mainly reflects a severity factor. It was, however, not valid for the alcohol intoxicated men, probably for the same reason as above and because the ambulance transport sometimes was more due to the intoxication than to injury severity.

\section{Utility of interview data}

Thus, this study shows that interview data for the 7 years preceding the interview will correctly identify about $60 \%$ of all injuries and $85 \%$ of the severe ones. The corresponding percentages for head injuries are $65 \%$ and $75 \%$ respectively. The interview method is the only way to cover life time and to reveal injuries not leading to medical attendance. Owing to the absence of index data there was no possibility of testing the validity of the interview data for the rest of the 'lifetime. However, there is evidence that the reporting frequency did not decrease markedly with time since the number of injuries reported in the study of men born in 1913 and 1923 was higher in the childhood and in the adult "active" period of life than later in life.

Interview data thus seem to give a fair measure of frequency of severe injuries and a comprehension of the magnitude of the underreporting of other injuries.

I am very grateful to Assistant Professor Kurt Svärdsudd for stimulating guidance and to Professor Sten Lindgren, Professor Gösta Tibblin and Doctor Daniel Stålhammar for encouragement and constructive criticism. The study was supported by grants from the Swedish Medical Research Council, the Medical Faculty of the University of Göteborg, the Göteborg Medical Society, Rådman och Fru Collianders Stiftelse and Göteborgs Kungliga Vetenskaps och Vitterhetssamhälle.

\section{References}

1 Tibblin G. High blood pressure in men aged 50-a population study of men born in 1913. PhD Thesis. Acta Med Scand 1967: suppl. 470.

${ }^{2}$ Rose GA, Blackburn H. Cardiovascular survey methods. World Health Organisation monograph series No. 56 World Health Organisation, Geneva, 1968.

${ }^{3}$ Larsson B. Obesity. A population study of men, with special reference to development and consequences for the health. PhD Thesis. University of Göteborg, Gotab Kungälv, Sweden, 1978:39-40.

${ }^{4}$ Welin L. Family study on ischemic heart disease and its risk factors. PhD Thesis. University of Göteborg, Uno Lundgren Tryckeri AB, Partille, Sweden, 1978.

${ }^{5}$ Linder FE. National health interview surveys. In: Trends in the study of morbidity and mortality. Public health papers, No 27, WHO, Geneva, 1965:78-111.

6 Westrin CG. The reliability of autoanamnesis. Scand J Soc Med 1974;2:23-35.

${ }^{7}$ Gordon JE, Gulati PV, Wyon JB. Reliability of recall data in traumatic accidents. Arch environm Hlth 1962;4:23-6.

${ }^{8}$ Vital and Health Statistics. Reporting of Hospitalization in the Health Interview Survey. National Center for Health Statistics, Public Health Service Publication No 1000 Series 2, No 6. Washington D.C. July 1965.

${ }^{9}$ Vital and Health Statistics. Health interview responses compared with medical records. National Center for Health Statistics, Public Health Service Publication No 1000 Series 2, No 7. Washington D.C. July 1965. 